\title{
Major Polymorphisms of Genes Involved in Homocysteine Metabolism in Malaria Patients in Ouagadougou, Burkina Faso
}

\author{
Noé Yameogo, ${ }^{1}$ Bapio Valérie Elvira Jean Télesphore Bazie, ${ }^{1,2}$ Abdoul Karim Ouattara, \\ Pouiré Yameogo, ${ }^{1}$ Tegwinde Rebeca Compaore, ${ }^{1}$ Dorcas Obiri-Yeboah, ${ }^{3}$ \\ Florencia Wenkuuni Djigma, ${ }^{1}$ Simplice Damintoti Karou, ${ }^{4}$ and Jacques Simpore ${ }^{1}$ \\ ${ }^{1}$ Laboratoire de Biologie Moléculaires et de Génétique (LABIOGENE), UFR-SVT, Université de Ouaga I Professeur Joseph KI-ZERBO, \\ Ouagadougou, Burkina Faso \\ ${ }^{2}$ Département Substances Naturelles (DSN), Institut de Recherche en Sciences Appliquées et Technologies (IRSAT), \\ Ouagadougou, Burkina Faso \\ ${ }^{3}$ Department of Microbiology and Immunology, School of Medical Sciences, University of Cape Coast, Cape Coast, Ghana \\ ${ }^{4}$ Ecole Supérieure des Techniques Biologiques et Alimentaires (ESTBA-UL), Université de Lomé, Lomé, Togo
}

Correspondence should be addressed to Simplice Damintoti Karou; simplicekarou@hotmail.com

Received 23 February 2017; Accepted 18 April 2017; Published 18 May 2017

Academic Editor: Donatella Taramelli

Copyright (c) 2017 Noé Yameogo et al. This is an open access article distributed under the Creative Commons Attribution License, which permits unrestricted use, distribution, and reproduction in any medium, provided the original work is properly cited.

This study analyzed the four main polymorphisms of the genes in homocysteine metabolism in malaria patients. Forty-two randomly selected subjects, diagnosed positive for Plasmodium falciparum, were included. The four genotypes were detected by realtime PCR using the MTHFR 677C>T, MTHFR 1298A>C, MTR 2756A>G, and MTRR 66A > G detection kit (Sacace Biotechnologies REF: T01002-96-S). The results revealed frequencies of 90\% 677CC, 10\% 677CT, and 00\% 677TT for MTHFR C677T; 78.6\% 1298AA, 19\% 1298AC, and 2.4\% 1298CC for MTHFR A1298C; 61.9\% 2756AA, 33.3\% 2756AG, and 4.8\% 2756GG for MTR A2756G; and $50 \%$ of $66 \mathrm{AA}, 45 \%$ of $66 \mathrm{AG}$, and 5\% of $66 \mathrm{GG}$ for MTRR A66G. Correlations were found between A2756G MTR genotypes and parasitaemia $(P=0.02)$, MTRR A66G and hemoglobin genotypes $(P=0.009)$, and MTHFR A1298C and sex $(P=0.01)$. This study demonstrated for the first time an association between the A2756G MTR alleles and Plasmodium falciparum malaria in Burkina Faso and gave an overview of the genotypic distribution of the major SNPs influencing the metabolism of homocysteine.

\section{Introduction}

Homocysteine is an intermediate amino acid in the metabolism of methionine. The plasma level in homocysteine depends on many factors, including the folate, B12, and B6 vitamins status. In addition, the genetic polymorphisms of Methylene Tetrahydrofolate Reductase (MTHFR) play a crucial role. Hyperhomocysteinaemia is a risk factor for several pathologies such as cardiovascular disease $[1,2]$, neurodegenerative diseases [3], renal insufficiency, and non-insulin-dependent diabetes. Studies have shown that hyperhomocysteinaemia is more common in the Caucasian population with more than $15 \%$ of people with high homocysteinaemia [4]. The plasma concentration of homocysteine is lower in sub-Saharan African populations compared to the Mediterranean $[5,6]$. This difference is due to the variable frequency of MTHFR polymorphisms between Westerners and Africans [7]. The frequency of the C677T allele varies with age in the African population. In Burkina Faso homocysteinaemia is low in the general population [5].

Plasmodium falciparum, the parasite responsible for the lethal cases of malaria, uses the pathway of polyamines essential to its proliferation and differentiation, thus imposing an oxidative stress on the host cell due to the use of glutathione $[8,9]$. This therefore reduces the remethylation of homocysteine to methionine and promotes the transsulfuration pathway. This situation can however be influenced by the enzymes involved in the metabolism of homocysteine. Several enzymes are involved in methionine synthesis from 
homocysteine. These are methylenetetrahydrofolate reductase (MTHFR), methionine synthase (MTR), and methionine synthase reductase (MTRR).

Depending on the polymorphisms of the genes responsible for the synthesis of these enzymes, the route of the remethylation can be promoted over that of the transsulfuration and vice versa. The development of Plasmodium in human is therefore influenced by the polymorphisms of these genes which intervene in the remethylation of homocysteine into methionine. Indeed, when the route of remethylation is favored, homocysteinaemia is low causing a low production of glutathione and thus reducing the development of Plasmodium in the human body. On the other hand, if this pathway is blocked, hyperhomocysteinaemia leads to an increase in the transsulfuration pathway and an accumulation of glutathione in the organism necessary for Plasmodium development.

Studies on the possible association of the polymorphisms of genes involved in homocysteine metabolism and malaria in Burkina Faso are missing. However, Chillemi et al. (2005) suggested that the determination of plasma homocysteine levels could be used as a measure of the severity of malaria infection [7]. The genes involved in the metabolism of homocysteine are highly polymorphic but only four major SNPs significantly influence it. It is therefore necessary to study the effect of these SNPs on the malaria evolution in Burkina Faso. In this study, the polymorphisms of the MTHFR genes (MTHFR C677T and MTHFR A1298C), MTR (MTR A2756G), and MTRR (MTRR A66G) were determined in malaria patients in Burkina Faso.

\section{Material and Methods}

2.1. Study Area. The present study was a prospective study conducted from September to November 2014 in Koubri. This is a rural municipality located in the southern Ouagadougou at approximately $25 \mathrm{~km}$, with the following geographical coordinates: $12^{\circ} 10^{\prime}$ north and $1^{\circ} 24^{\prime}$ west. Koubri has an average annual temperature of $28.2^{\circ} \mathrm{C}$ and it falls on average $780 \mathrm{~mm}$ of rain per year. However, the locality has numerous reservoirs of water that make the presence of mosquitoes vectors persistent throughout the year, so explaining the endemicity of malaria in the area.

2.2. Study Population. The study initially included 182 patients (1 to 79 years) who underwent malaria rapid diagnosis test, SD BIOLINE Malaria Ag P.f/Pan, which enables the detection of the Plasmodium falciparum HPRII antigen (histidine II-rich protein) and Plasmodium lactic dehydrogenase (pLDH) common to Plasmodium species in human whole blood. Tick smears were made for each patient for the confirmation of plasmodial species and the parasite count. Finally, the 42 patients with the highest parasite density (density superior to 3000 parasite $\mu \mathrm{L}$ of blood) were selected for the G-6-PD deficiency study. The age and the antimalarial drugs intakes were directly recorded prior to the blood sampling.
2.3. Blood Sampling. From the 42 selected patients, $5 \mathrm{~mL}$ of venous blood was collected in two EDTA impregnated tubes. The first tube was used for the hematological analysis; the second was centrifuged to discard plasma and the pellets were stored at $-80^{\circ} \mathrm{C}$ until use for nucleic acid extractions.

2.4. Hematological Analysis. Platelet count and hemoglobin were determined with total venous blood using the ABX micro 60 automate. Hemoglobin electrophoresis was performed at alkaline $\mathrm{pH}$ (tris-glycine buffer $\mathrm{pH}$ 9.5) on cellulose acetate strip (CELLOGEL $5.7 \times 14 \mathrm{~cm}$ ). In brief, whole blood was washed three times with $0.9 \% \mathrm{NaCl}$ by successive centrifugations at $3000 \mathrm{rpm}$ for $5 \mathrm{~min}$. Finally, the red cell pellet was lysed with $500 \mu \mathrm{L}$ of $1 \%$ saponin and the sample spots were deposited on the CELLOGEL with capillary tubes. The migration was made with $150 \mathrm{~V}$ in $60 \mathrm{~min}$.

2.5. DNA Extraction and Genotyping of Polymorphisms. The extraction of DNA from the blood pellet was carried out using the salting out method $[15,16]$. The Biodrop $\mu$ LITE (Isogen Life Science N.V./S.A, Temse, Belgium) was used for DNA extracts purity and final concentration assessment.

The samples genotyping with real time PCR was carried out using "Real Time PCR kit for detection of MTHFR 677C $>$ T, MTHFR 1298A $>$ C, MTR 2756A $>$ G, and MTRR 66A>G" (Sacace Biotechnologies, REF: T01002-96-S). SaCycler-96 (Sacace Biotechnologies ${ }^{\circledR}$; Como, Italy) was used for amplification. Thermocycling was performed at $80^{\circ} \mathrm{C}$ for 2 min and $94^{\circ} \mathrm{C}$ for $3 \mathrm{~min}$ and then 40 cycles at $94^{\circ} \mathrm{C}$ for $15 \mathrm{sec}$ and $64^{\circ} \mathrm{C}$ (annealing temperature) for $40 \mathrm{sec}$.

2.6. Statistical Analysis. The data was processed using Excel 2010 (Microsoft) and SPSS ${ }^{\circledR}$ software version 20 (SPSS Inc., Chicago, USA). The Pearson Chi test was used for comparisons and any $P$ value $<0.05$ was considered statistically significant.

2.7. Ethical Considerations. The study was approved by the Ethics Committee for Health Research in Burkina Faso (Deliberation number 2014-9-128). Adults have given their free and informed consent for their participation in the study while the parents or guardians of the minors have given their approval for the participation of the minor.

\section{Results}

3.1. Sociodemographic and Paraclinical Data. The study involved $69.05 \%(29 / 42)$ men and $30.95 \%(13 / 42)$ women, the majority of whom were children with $14.28 \%(6 / 42)$ over 20 years of age (Table 1). The mean age was $14.22 \pm 12.26$ years. In the study population $52.38 \%(22 / 42)$ of the patients were on antimalarial treatment before the thick smear was performed, while $47.62 \%$ (20/42) of them did not yet receive any treatment. Among the screened patients, $54.76 \%$ presented a parasitaemia above 10,000 trophozoites/ $\mu \mathrm{L}$ while $11.90 \%$ had a parasitaemia between 3,000 and 10,000 trophozoite $/ \mu \mathrm{L}$. However, the parasitaemia was below 3,000 trophozoites $/ \mu \mathrm{L}$ for $33.34 \%$ patients. 


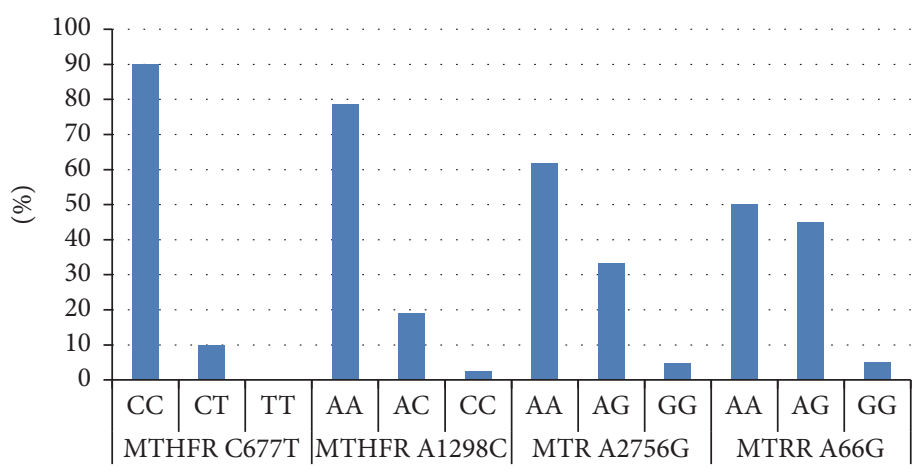

FIgURE 1: Polymorphisms distribution among screened people.

TABLE 1: Sociodemographic and biological data.

\begin{tabular}{|c|c|c|}
\hline Characteristics & $N$ & $(\%)$ \\
\hline \multicolumn{3}{|l|}{ Treatment } \\
\hline Yes & 22 & 52.38 \\
\hline No & 20 & 47.62 \\
\hline \multicolumn{3}{|c|}{ Parasitaemia (parasite/ $\mu \mathrm{L}$ ) } \\
\hline$<3,000$ & 14 & 33.33 \\
\hline$[3,000-10,000[$ & 5 & 11.90 \\
\hline$>10,000$ & 23 & 54.76 \\
\hline \multicolumn{3}{|c|}{ Hemoglobin $\left(\mathrm{g} \cdot \mathrm{L}^{-1}\right)$} \\
\hline$<10$ & 10 & 23.81 \\
\hline $10-12$ & 15 & 35.71 \\
\hline$>12$ & 17 & 40.48 \\
\hline \multicolumn{3}{|l|}{ Platelets count } \\
\hline$<15,000$ & 14 & 33.33 \\
\hline$\geq 15,000$ & 28 & 66.67 \\
\hline \multicolumn{3}{|c|}{ Hemoglobin genotypes } \\
\hline AA & 24 & 57.14 \\
\hline $\mathrm{AC}$ & 14 & 33.33 \\
\hline AS & 2 & 4.76 \\
\hline $\mathrm{CC}$ & 1 & 2.38 \\
\hline SC & 1 & 2.38 \\
\hline \multicolumn{3}{|l|}{ Sex } \\
\hline M & 29 & 69.05 \\
\hline $\mathrm{F}$ & 13 & 30.95 \\
\hline \multicolumn{3}{|l|}{ Age groups } \\
\hline$\leq 5$ & 11 & 26.19 \\
\hline $5-20$ & 25 & 59.52 \\
\hline$>20$ & 6 & 14.28 \\
\hline
\end{tabular}

With regard to the anemia, $40.48 \%$ patients were not anemic $\left(\mathrm{Hb}>12 \mathrm{~g} \mathrm{~L}^{-1}\right)$, while $35.72 \%(15 / 42)$ had moderate anemia $\left(10<\mathrm{Hb}<12 \mathrm{~g} \mathrm{~L}^{-1}\right)$ and $23.80 \%(10 / 42)$ had anemia $\left(\mathrm{Hb}<10 \mathrm{~g} \mathrm{~L}^{-1}\right)$. It should also be noted that $33.33 \%(14 / 32)$ of patients had thrombocytopenia compared to $66.67 \%(28 / 42)$ with normal platelet count. The frequency of the HbAA genotype was $57.14 \%$ (27/42) with one of the patients $(0.02 \%)$ presenting major sickle cell syndrome (SC).

3.2. Gene Polymorphisms. Figure 1 shows the PCR analysis of the four polymorphisms studied. The MTHFR A1298C, MTR A2756G, and MTRR A66G genes all showed homozygous mutants with the exception of MTHFR C677T. The correlation between different polymorphisms studied and hemoglobin genotypes gave a statistically significant difference for the MTRR A66G gene $(P=0.009)$ (Table 2). An association between A2756G MTR genotypes and parasitaemia was also found $(P=0.02)$. Individuals with 2756AA genotype predominantly $(19 / 26)$ had high parasitaemia (>10,000 trophozoites/ $\mu \mathrm{L}$ of blood). The analysis of these polymorphisms according to the genus revealed a statistically significant difference for the MTHFR A1298C gene $(P=0.01)$ with more male subjects carrying the MTHFR 1298AA genotype (26/29 or $89.65 \%)$. Finally the data recorded in the present study were compared with previous data recorded in five other countries, namely, China, Pakistan, Brazil, South Korea, and Sweden (Table 3). The frequencies for MTHFR C677T recorded in the present study differed from those met in these previous studies. Hence the genotype CC was more encountered but the genotypes CT and TT were not frequently encountered. The frequencies for MTHFR A1298C are similar to those met in China and different from those of the other studies. The genotype MTR A2756G seemed to follow the same trends in both studies.

\section{Discussion}

This study described the MTHFR C677T, MTHFR A1298C, MTR A2756G, and MTRR A66G mutations. The genotypic frequencies found for the MTHFR C677T mutation are similar to those already reported in Burkina Faso [7]. Our results, however, differ from those reported in Sweden $(46.3 \%$ $677 \mathrm{CC}, 43.4 \% 677 \mathrm{CT}$, and $10.3 \% 677 \mathrm{TT}$ ) in the mucosa of patients with colorectal cancer [13]; $28.6 \%$ 677CC, $44.9 \%$ $677 \mathrm{CT}$, and $26.5 \% 677 \mathrm{TT}$ reported in patients with lymphoblastic leukemia in the Chinese population [17]; $51.4 \%$ $677 \mathrm{CT}, 41.4 \%$ 677CT, and 7.1\% 677TT reported in Brazil 
TABLE 2: Correlation between genotypes and selected patient characteristics.

\begin{tabular}{|c|c|c|c|c|c|c|c|c|c|c|c|c|c|c|}
\hline \multirow{2}{*}{ Genes } & \multirow{2}{*}{ Genotypes } & \multicolumn{5}{|c|}{ Hemoglobin genotypes } & \multirow{2}{*}{$P$} & \multicolumn{3}{|c|}{ Parasitaemia } & \multirow{2}{*}{$P$} & \multicolumn{2}{|c|}{ Sex } & \multirow{2}{*}{$P$} \\
\hline & & $\mathrm{AA}$ & $\mathrm{AC}$ & AS & $\mathrm{CC}$ & SC & & $<3000$ & $3000-10000$ & $>10000$ & & $\mathrm{M}$ & $\mathrm{F}$ & \\
\hline \multirow{3}{*}{ MTHFR C677T } & $\mathrm{CC}$ & 20 & 12 & 0 & 2 & 2 & \multirow{3}{*}{0.660} & 16 & 6 & 14 & \multirow{3}{*}{0.380} & 22 & 14 & \multirow{3}{*}{0.457} \\
\hline & $\mathrm{CT}$ & 4 & 0 & 0 & 0 & 0 & & 0 & 0 & 4 & & 4 & 0 & \\
\hline & $\mathrm{TT}$ & 0 & 0 & 0 & 0 & 0 & & 0 & 0 & 0 & & 0 & 0 & \\
\hline \multirow{3}{*}{ MTHFR A1298C } & AA & 22 & 8 & 2 & 1 & 0 & \multirow{3}{*}{0.160} & 11 & 3 & 19 & \multirow{3}{*}{0.605} & 26 & 7 & \multirow{3}{*}{0.01} \\
\hline & $\mathrm{AC}$ & 2 & 5 & 0 & 0 & 1 & & 3 & 2 & 3 & & 2 & 6 & \\
\hline & $\mathrm{CC}$ & 0 & 1 & 0 & 0 & 0 & & 0 & 0 & 1 & & 1 & 0 & \\
\hline \multirow{3}{*}{ MTR A2756G } & $\mathrm{AA}$ & 17 & 8 & 1 & 0 & 0 & \multirow{3}{*}{0.717} & 4 & 3 & 19 & \multirow{3}{*}{0.02} & 19 & 7 & \multirow{3}{*}{0.09} \\
\hline & AG & 6 & 5 & 1 & 1 & 1 & & 9 & 2 & 3 & & 10 & 4 & \\
\hline & GG & 1 & 1 & 0 & 0 & 0 & & 1 & 0 & 1 & & 0 & 2 & \\
\hline \multirow{3}{*}{ MTRR A66G } & AA & 14 & 6 & 0 & 0 & 0 & \multirow{3}{*}{0.009} & 4 & 2 & 14 & \multirow{3}{*}{0.185} & 16 & 4 & \multirow{3}{*}{0.182} \\
\hline & AG & 8 & 8 & 1 & 1 & 1 & & 9 & 2 & 8 & & 10 & 9 & \\
\hline & GG & 0 & 0 & 1 & 0 & 0 & & 1 & 0 & 0 & & 1 & 0 & \\
\hline
\end{tabular}

in patients with chronic hepatitis C [14]; and 7.8\% 677TT reported in children in the USA [18]. These differences could be explained by the type of population and the patients studied. Indeed, the minor allele " $\mathrm{T}$ " is more prevalent in the white and Hispanic population and almost absent in the black populations of Africa and the United States of America [19]. Frequencies of $88.1 \%$ and $11.9 \%$ for the A and C alleles were, respectively, observed for the MTHFR A1298C mutation in our study. These results are comparable to the allelic frequencies ( $87.4 \% \mathrm{~A}$ and $12.6 \% \mathrm{C}$ ) reported in 2002 by Simporè et al. [6] in Burkina Faso.

Genotypic frequencies for this gene (78.6\% AA, 19\% AC, and $2.4 \% \mathrm{CC}$ ) in our study are also similar to those found in $20-45$ years of age $(79.27 \% \mathrm{AA}, 17.07 \% \mathrm{AC}$, and $3.66 \% \mathrm{CC})$ in Burkina Faso [7].

Our results, however, differ from the genotypic frequencies $(66.8 \% \mathrm{AA}, 29.3 \% \mathrm{AC}$, and $3.9 \% \mathrm{CC})$ reported in Chinese Han adults [11]; 67.8\% AA, 30.3\% AC, and 1.9\% CC reported in Koreans with silent cerebral infarction [12]; and 20.8\% AA, 48.7\% AC, and 30.5\% CC found in Pakistan [10]. These variations could be explained by ethnic origin and geographical areas.

The results of our study for the mutation MTR A2756G (61.9\% AA, 33.3\% AG, and 4.8\% GG) are also different from the genotypic frequencies (52.4\% AA, 38.8\% AG, and $8.8 \%$ GG) reported in Pakistan [10] and in Jordan (83.50\% AA, $14.46 \% \mathrm{AG}$, and $2.04 \% \mathrm{GG}$ ) [20] whereas they are similar to frequencies (63.6\% AA, 31.3\% GA, and 5.1\% GG) reported in Sweden [13]. The genotypic frequencies of the MTRR A66G mutation revealed a 5\% MTRR 66GG percentage close to the $6.6 \%$ reported in China [11] but different from the $34.5 \%$ reported in Sweden [13]. The small size of our study population and the uniqueness of our subjects (positive for malaria and not randomly selected in the general population) could explain these differences.

A correlation between MTRR A66G and hemoglobin genotypes was observed in this study. A2756G MTR genotype and parasitaemia showed a statistically significant association; MTR 2756AA individuals with predominantly high parasitaemia ( $>10,000$ trophozoites $/ \mu \mathrm{L}$ of blood) could be more susceptible to malaria than others. An association between this mutation and malaria has been reported in the Northeast region of India [21]. These results demonstrate a probable selection of these polymorphisms under malaria pressure. A statistically significant difference in MTHFR A1298C genotypes by sex was also observed. Male individuals would be more affected by the MTHFR 1298AA genotype $(26 / 29)$.

The small size of our study population because of limited financial resources therefore suggests the need for confirmation of these observations on a sufficiently large study population. The NFS results were comparable to those found in the general population. Only platelet and hemoglobin levels were used in this study to evaluate the correlations with the different mutations.

The effect of the mutations was studied on certain parameters such as variations in the number of white blood cells that may be due to other pathologies outside malaria which were difficult to assess. Despite the small sample size, this is the first time that all four polymorphisms have been studied in the same group of individuals in Ouagadougou, Burkina Faso.

Burkina Faso is a malaria endemic country with a high frequency of host resistance polymorphisms to Plasmodium falciparum malaria. Our study provided an overview of the genotypic frequencies of four major polymorphisms (MTHFR C677T, MTHFR A1298C, MTR A2756G, and MTRR A66G) for the genes involved in homocysteine metabolism correlated with simple malaria. Several associations such as MTRR A66G and hemoglobin genotypes; MTR A2756G and Plasmodium falciparum; and MTHFR A1298C infection and sex were observed and suggest a large enough sample for further analysis. 


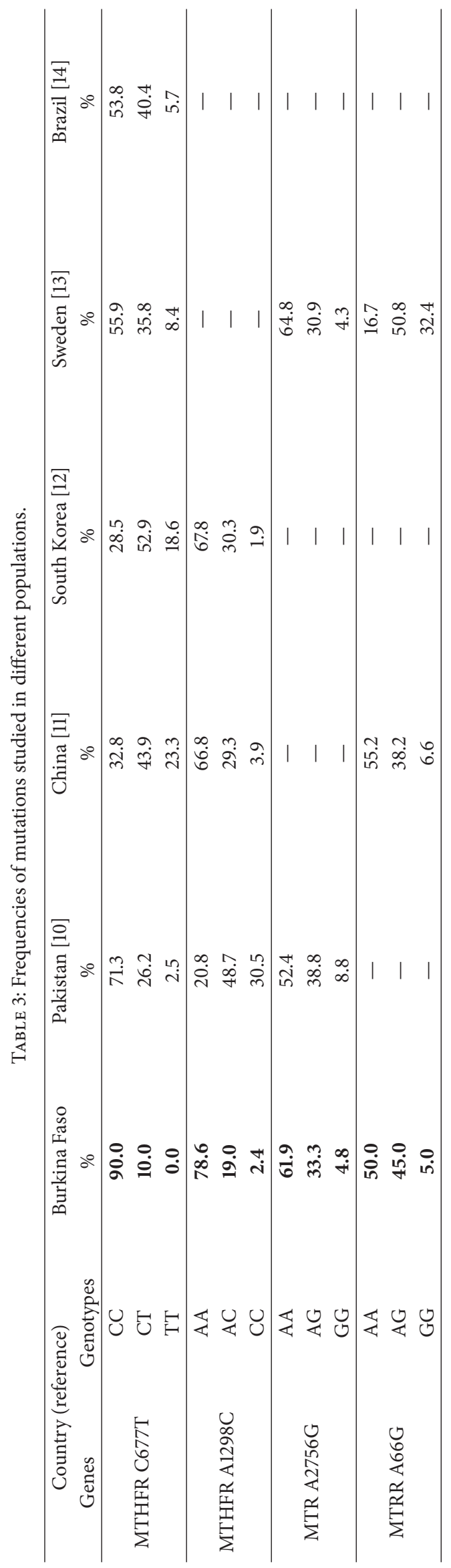




\section{Conflicts of Interest}

The authors declare that they have no conflicts of interest.

\section{Acknowledgments}

The authors express their sincere gratitude to the entire staff of CERBA/LABIOGENE for their assistance to carry out this study. Their thanks also go to the Italian Episcopal Conference (CEI) and West African Economic and Monetary Union (UEMOA) (through the PACER2 program) for their financial support.

\section{References}

[1] P. Durand, M. Prost, and D. Blache, "Folate deficiencies and cardiovascular pathologies," Clinical Chemistry and Laboratory Medicine, vol. 36, no. 7, pp. 419-429, 1998.

[2] A. Laraqui, A. Allami, A. Carrié et al., "Influence of methionine synthase (A2756G) and methionine synthase reductase (A66G) polymorphisms on plasma homocysteine levels and relation to risk of coronary artery disease," Acta Cardiologica, vol. 61, no. 1, pp. 51-61, 2006.

[3] M. A. Smach, S. Naffeti, B. Charfeddine et al., "Homocysteine, vitamin B-12, folic acid and the cognitive decline in the elderly," Pathologie Biologie, vol. 61, no. 5, pp. 184-192, 2013.

[4] X. Roblin, J. Pofelski, and J.-P. Zarski, "Steatosis, chronic hepatitis virus $\mathrm{C}$ infection and homocysteine," Gastroenterologie Clinique et Biologique, vol. 31, no. 4, pp. 415-420, 2007.

[5] J. Simporè, S. Pignatelli, S. Barlati, M. Malaguarnera, and S. Musumeci, "Plasma homocysteine concentrations in a healthy population living in Burkina Faso," Current Therapeutic Research-Clinical and Experimental, vol. 61, no. 9, pp. 659-668, 2000.

[6] J. Simporè, S. Pignatelli, C. Meli, M. Malaguarnera, R. Chillemi, and S. Musumeci, "Nutritional and racial determinants of the increase in plasma homocysteine levels after methionine loading," Current Therapeutic Research-Clinical and Experimental, vol. 63, no. 7, pp. 459-473, 2002.

[7] R. Chillemi, J. Simpore, S. Persichilli, A. Minucci, A. D’Agata, and S. Musumeci, "Elevated levels of plasma homocysteine in postmenopausal women in Burkina Faso," Clinical Chemistry and Laboratory Medicine, vol. 43, no. 7, pp. 765-771, 2005.

[8] J. Vega-Rodríguez, B. Franke-Fayard, R. R. Dinglasan et al., “The glutathione biosynthetic pathway of Plasmodium is essential for mosquito transmission," PLoS Pathogens, vol. 5, no. 2, Article ID e1000302, 2009.

[9] E.-M. Patzewitz, E. H. Wong, and S. Müller, "Dissecting the role of glutathione biosynthesis in Plasmodium falciparum," Molecular Microbiology, vol. 83, no. 2, pp. 304-318, 2012.

[10] M. Yakub, N. Moti, S. Parveen, B. Chaudhry, I. Azam, and M. P. Iqbal, "Polymorphisms in MTHFR, MS and CBS genes and homocysteine levels in a Pakistani population," PLOS ONE, vol. 7, no. 3, Article ID e33222, 2012.

[11] B. Yang, Y. Liu, Y. Li et al., "Geographical distribution of MTHFR C677T, A1298C and MTRR A66G gene polymorphisms in China: findings from 15357 adults of han nationality," PLoS ONE, vol. 8, no. 3, Article ID e57917, 2013.

[12] I. B. Han, O. J. Kim, J. Y. Ahn et al., "Association of methylenetetrahydrofolate reductase (MTHFR $677 \mathrm{C}>\mathrm{T}$ and $1298 \mathrm{~A}>\mathrm{C}$ ) polymorphisms and haplotypes with silent brain infarction and homocysteine levels in a Korean population," Yonsei Medical Journal, vol. 51, no. 2, pp. 253-260, 2010.

[13] Y. Wettergren, E. Odin, G. Carlsson, and B. Gustavsson, "MTHFR, MTR, and MTRR polymorphisms in relation to p16INK4A hypermethylation in mucosa of patients with colorectal cancer," Molecular Medicine, vol. 16, no. 9-10, pp. 425432, 2010.

[14] E. R. Siqueira, C. P. Oliveira, M. T. Muniz, F. Silva, L. M. Pereira, and F. J. Carrilho, "Methylenetetrahydrofolate reductase (MTHFR) C677T polymorphism and high plasma homocysteine in chronic hepatitis $\mathrm{C}(\mathrm{CHC})$ infected patients from the Northeast of Brazil," Nutrition Journal, vol. 10, no. 1, article 86, 2011.

[15] S. A. Miller, D. D. Dykes, and H. F. Polesky, "A simple salting out procedure for extracting DNA from human nucleated cells," Nucleic Acids Research, vol. 16, no. 3, article 1215, 1988.

[16] A. K. Ouattara, C. Bisseye, B. V. Bazie et al., "Glucose-6phosphate dehydrogenase (G6PD) deficiency is associated with asymptomatic malaria in a rural community in Burkina Faso," Asian Pacific Journal of Tropical Biomedicine, vol. 4, no. 8, pp. 655-658, 2014.

[17] X. Li, Q. Liao, S. Zhang, and M. Chen, "Association of methylenetetrahytrofolate reductase (MTHFR) C677T and A1298C polymorphisms with the susceptibility of childhood acute lymphoblastic leukaemia (ALL) in Chinese population," European Journal of Medical Research, vol. 19, no. 1, article 5, 2014.

[18] E. Joachim, N. A. Goldenberg, T. J. Bernard, J. Armstrong-Wells, S. Stabler, and M. J. Manco-Johnson, "The methylenetetrahydrofolate reductase polymorphism (MTHFR c.677C > T) and elevated plasma homocysteine levels in a U.S. pediatric population with incident thromboembolism," Thrombosis Research, vol. 132, no. 2, pp. 170-174, 2013.

[19] L. D. Botto and Q. Yang, "5,10-Methylenetetrahydrofolate reductase gene variants and congenital anomalies: a HuGE review," American Journal of Epidemiology, vol. 151, no. 9, pp. 862-877, 2000.

[20] H. Y. Alfarra, S. R. Alfarra, and M. F. Sadiq, "Neural tube defects between folate metabolism and genetics," Indian Journal of Human Genetics, vol. 17, no. 3, pp. 126-131, 2011.

[21] D. Mirgal, K. Ghosh, J. Mahanta, P. Dutta, and S. Shetty, "Possible selection of host folate pathway gene polymorphisms in patients with malaria from a malaria endemic region in North East India," Transactions of the Royal Society of Tropical Medicine and Hygiene, vol. 110, no. 5, pp. 294-298, 2016. 


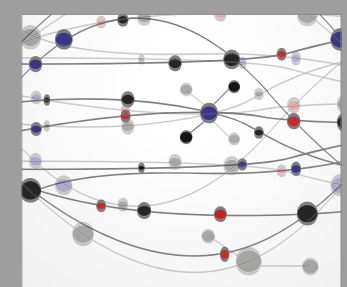

The Scientific World Journal
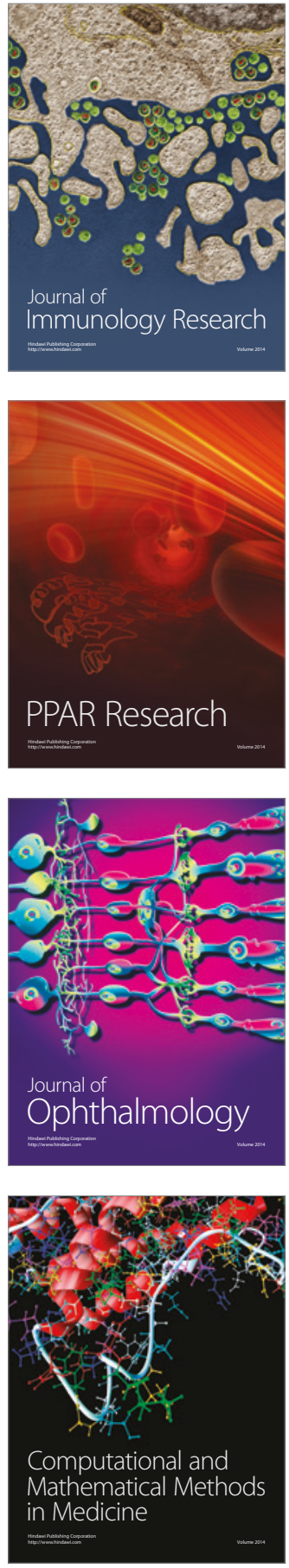

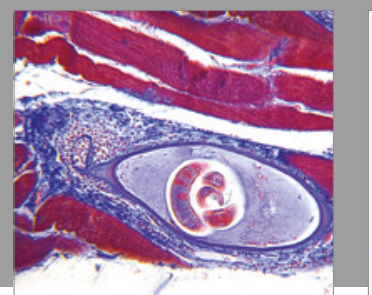

Gastroenterology Research and Practice
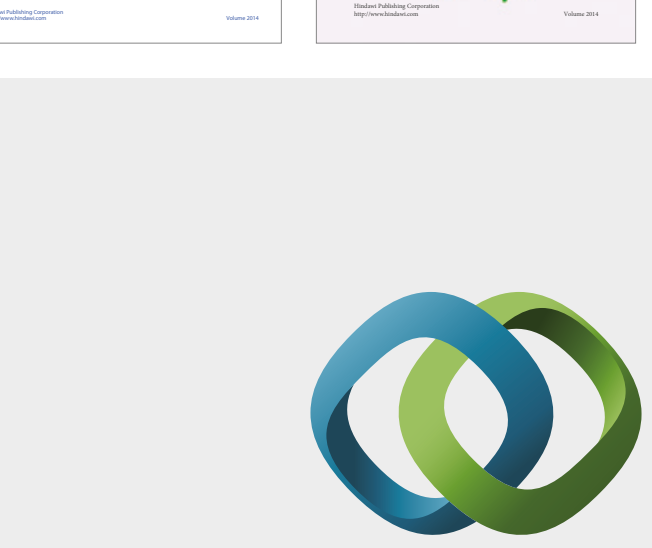

\section{Hindawi}

Submit your manuscripts at

https://www.hindawi.com
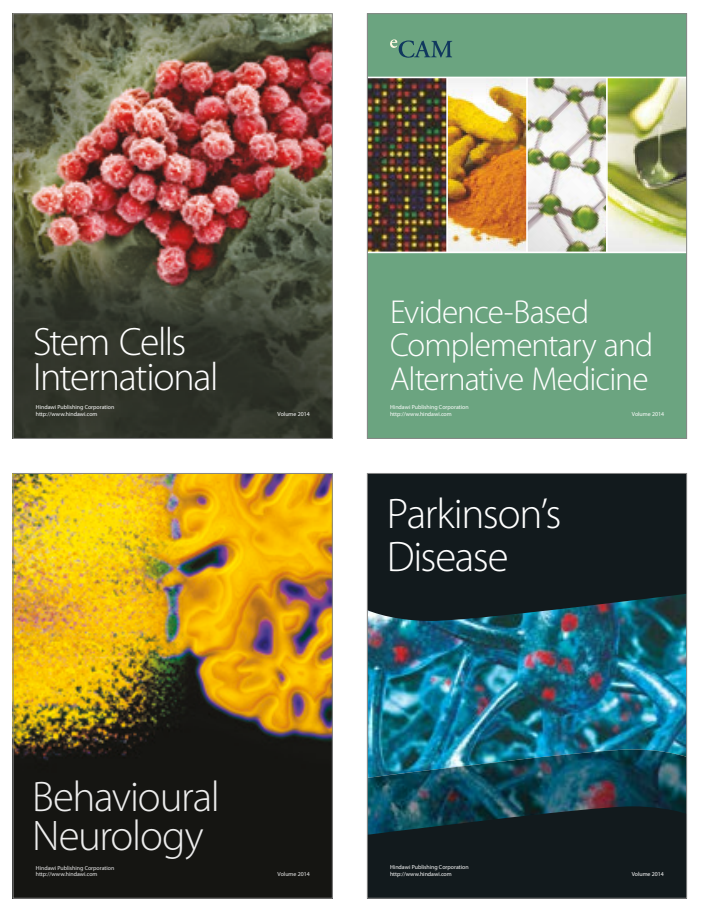
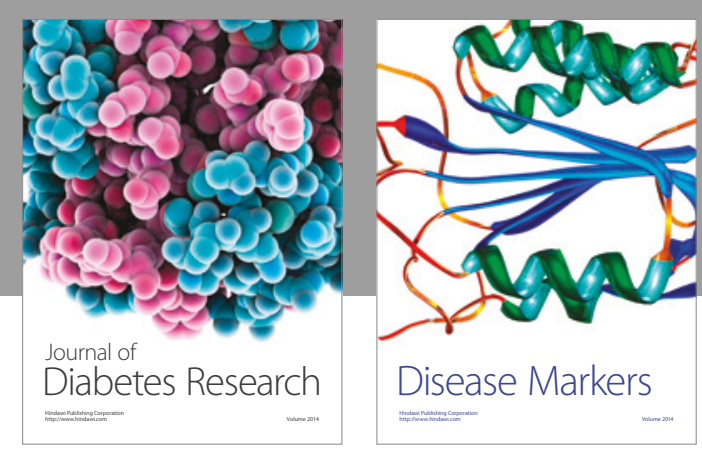

Disease Markers
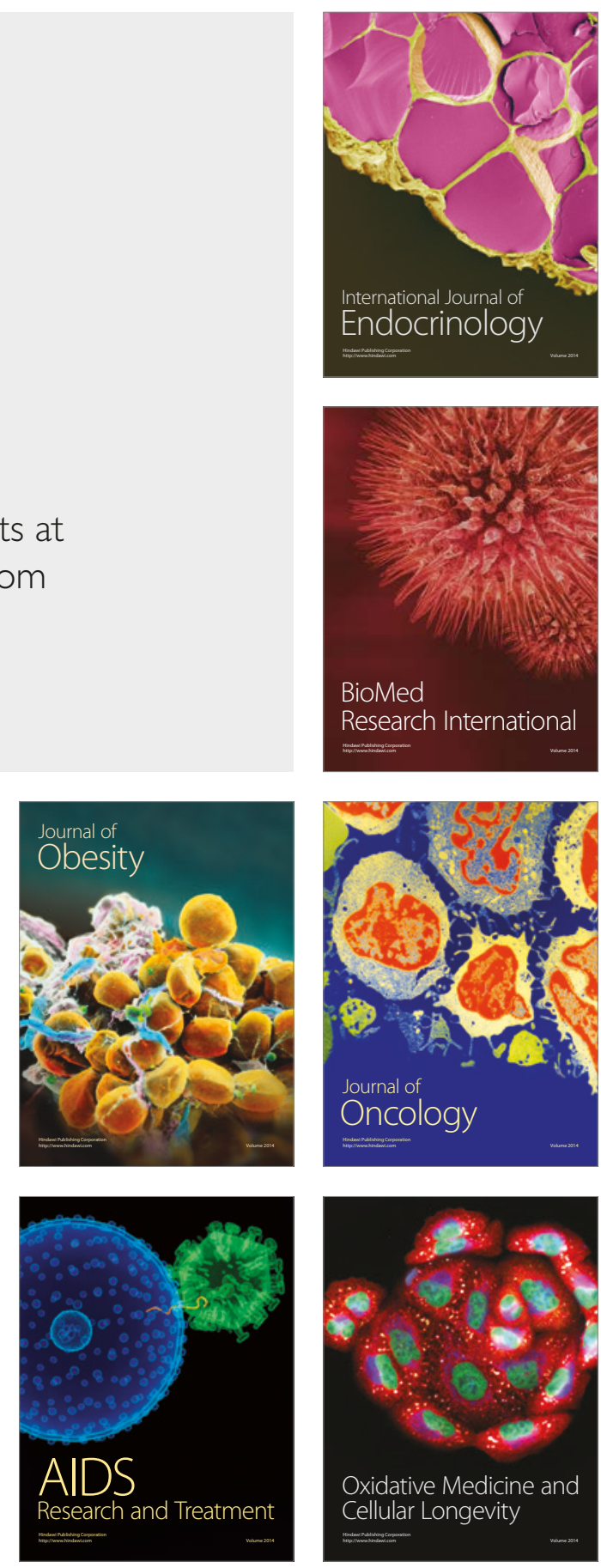